\title{
THE UNEMPLOYED WORKERS' PERCEPTIONS OF STRESS AND EMPLOYMENT PROSPECTS IN MACEDONIA: THE ROLE OF ALTERNATIVE ADJUSTMENT MECHANISMS
}

Dimitar Nikoloski, Ljupcho Pechijareski

\section{Abstract}

Depressed labour market conditions in Macedonia manifested by high and persistent unemployment rate, strong segmentation and prevailing long-term unemployment is considered as a heritage of more than two decades long period of transition. Unemployment has a number of negative consequences such a decreased income which is assumed to influence the subjective experience of unemployment. The negative macroeconomic shocks in Macedonia have been mitigated due to the strengthened role of alternative labour market adjustment mechanisms such as: employment in the informal sector, emigration and inactivity. However, their impact on the unemployed workers' perceptions of stress and future labour market prospects is less clear-cut. In this paper we use results from a survey carried out on a sample of unemployed workers in Macedonia in order to identify the psychological implications of unemployment by assessing the perceived stress and employment prospects with particular reference to the role of alternative labour market adjustment mechanisms.

Keywords: Labour market, unemployment, stress, employment prospect.

JEL classification: 131, J64

\section{INTRODUCTION}

The past two decades Macedonia has gone through the process of transition which is still shaping the social, political and economic ambience in the country. As a part of South-Eastern Europe, the Macedonian economic growth is constrained by the general regional predispositions, which amongst other things are determined by the political instability of the region. Hence, the economic performance of the South-Eastern European countries (SEECs) has not been strong enough compared to Central-Eastern Europe countries (CEECs), which already take part of the European Union. In this sense, Macedonia and other SEECs, are known as 'lagging reformers' with regard to completion of the reforms in all spheres of the society.
The initial transitional recession has inter alia manifested salient effects on the labour
Dimitar Nikoloski, $\mathrm{PhD}$
Associate professor
University "St. Kliment Ohridski"- Bitola
Faculty of Economics - Prilep
E-mail:dimitar.nikoloski@uklo.edu.mk
Ljupcho Pechijareski, PhD
Full professor
University "St. Kliment Ohridski" - Bitola
Faculty of Economics - Prilep
E-mail: Ipeci@yahoo.com 
market performance (Pechijareski and Rocheska 1998). Generally, the transitional reforms initially had negative effects on labour markets, which were manifested in declining participation rates and in persistent high unemployment. The processes of ownership restructuring and sectoral reallocation assumed a large-scale transformation of state owned firms into privatised ones and, a reallocation of a substantial part of the labour force from the manufacturing and agricultural sectors towards the expanding service sector (Blanchard 1997). The experience in almost all transition countries, including Macedonia shows that the creation of new jobs in the emerging private sector was not initially strong enough to absorb the mass of workers laid-off from the restructured state-owned firms. At the same time, the mismatch between the skill requirements of newly created jobs and effective skills owned by the workers has become a substantial problem (Svejnar 2002). Consequently, the labour markets in early transition became less dynamic with a relatively stagnant unemployment pool leading to increases in unemployment and especially long-term unemployment (Cazes and Nesporova 2003). The initial 'transitional unemployment' differed in several aspects from other types of unemployment in that it was characterised by pronounced labour market segmentation, long average duration of unemployment and a low probability of exiting unemployment into employment (Nikoloski 2009).

The negative macroeconomic shocks in Macedonia have been mitigated due to the strengthened role of alternative labour market adjustment mechanisms such as: employment in the informal sector, emigration and inactivity. These mechanisms cushion the social implications of unemployment by absorbing a part of unemployed workforce and providing additional incomes for their households. However, their impact on the unemployed workers' perceptions of stress and future labour market prospects is less clearcut. Thus, examining the interplay between the alternative labour market adjustment mechanisms, from one side and the unemployed workers psychological wellbeing represents a challenging research task. In this context, our research question is whether the alternative forms of labour market adjustment play significant role in dealing with unemployment and, consequently influence the perceived stress and optimism about finding a new job.

The aim of the paper is to assess the unemployed workers' perceptions of stress and employment prospects as a function of various socio-demographic variables, by paying particular attention to the role of alternative forms of labour market adjustment in Macedonia. For this purpose we use the empirical results from a survey of registered unemployed workers. To our knowledge this is the first study addressing this issue in Macedonia, which brings two main contributions. First, it reveals the psychological implications of unemployment and alternative coping strategies on the unemployed workers' perceptions of stress and future employment prospects. Second, the results from the analysis can be used in designing appropriate social and labour market policies aiming to improve the psychological wellbeing of disadvantaged labour market segments.

The paper is structured as follows. In section 2 we review the general characteristics of the Macedonian labour market. Next, in section 3 we present the theoretical background, whereas the empirical assessment of unemployed workers' perceptions of stress and employment prospects is subject of analysis in section 4. Finally, in section 5 we provide discussion and formulate recommendations for the labour market policies that focus on improving the psychological wellbeing of the unemployed population.

\section{MACEDONIAN LABOUR MARKET PERFORMANCE}

In order to investigate the features of the Macedonian labour market during transition, it is appropriate to divide the transitional period into two sub-periods. The first period encompasses the transformational recession from 1990 to 1995 , with the second period starting immediately thereafter and lasting until the present. The changes of the unemployment rate in relative terms during the business cycle are rather small, which reflects the depressed characteristics of the Macedonian labour market (Nikoloski 2009). The dynamics of the unemployment rate in Macedonia during the period 1996-2015 is shown on Figure 1.

The first Labour Force Survey (LFS) in Macedonia was conducted in 1996, and since then we have detailed data concerning labour market trends. During the period 1996-2003, the Macedonian LFS was conducted on a yearly basis, whereas since 2004 it is conducted as a continuous survey throughout the year with quarterly processing of data. For the period prior to 1996 we can explore labour market trends based on the number of registered unemployed workers. According to both sources of data we can generally distinguish several features of Macedonian labour market presented as follows.

During the initial phase of transition, the labour force participation and employment rates fell for most of this period, while the unemployment rate steadily 
Figure 1: The unemployment rate in Macedonia 1996-2015

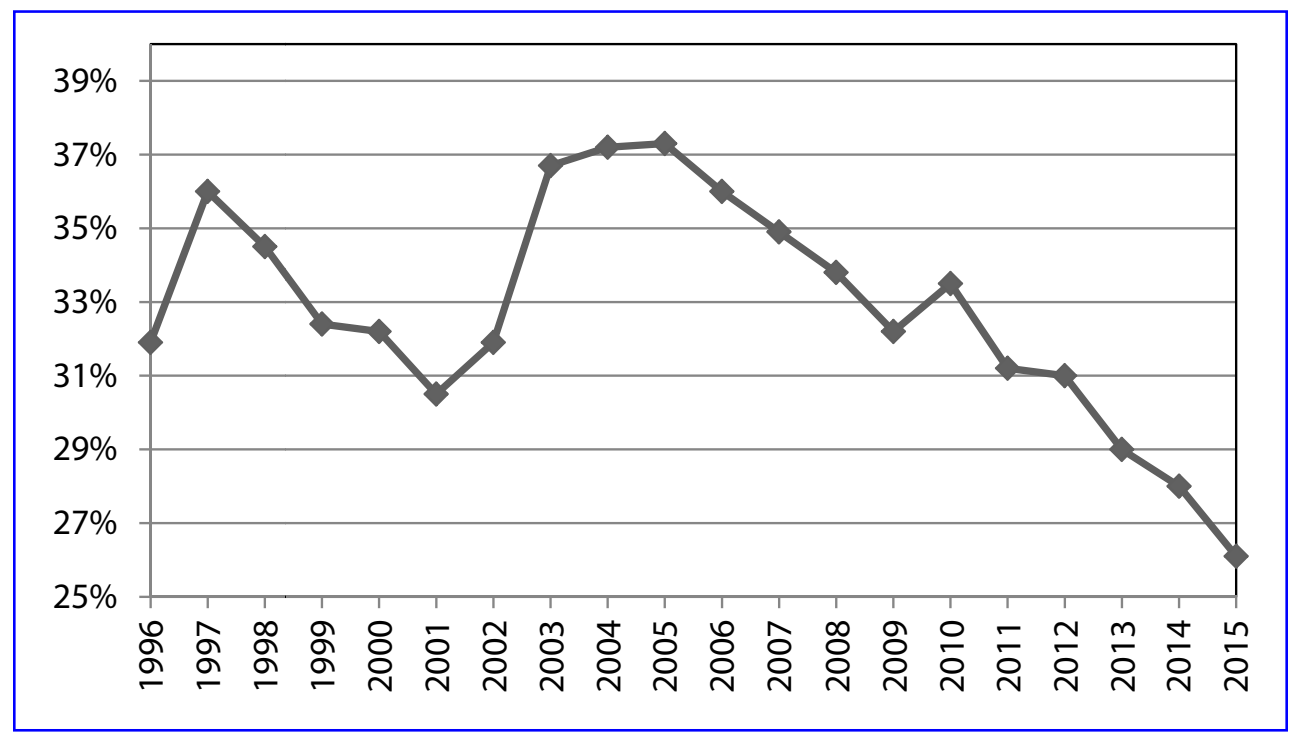

Source: Macedonian Statistical Office, Labour Force Survey

increased. These trends are in line with the normal labour market patterns found in other transition countries i.e. declining employment under the initial shock of recession and subsequent persistence of sluggish demand for labour. Although, the mature phase of transition is characterised by broad stability in all three rates, we can observe recessions in 2001 primarily caused by the political instability and in 2009 due to the global economic crisis. Namely, Macedonia has not remained apart from the negative global macroeconomic tendencies engendered by the recent economic crisis. Although recession has started one year later, after three consecutive quarters of negative GDP growth the macroeconomic performance by the end of 2009 has already demonstrated some signs of recovery and since then the unemployment rate has manifested continuous declining trend.

The sectoral reallocation of labour has been characterised by a significant increase of subsistence agriculture and other non-standard forms of employment at the expense of rapid shrinkage of employment in manufacturing (European Training Foundation 2007). These trends in employment by sectors indicate that in Macedonia new jobs are not predominantly created in the more productive industries and service sector, but rather in agriculture and low productivity services (Micevska 2008). The increase in the share of employment in agriculture suggests that this sector has become a buffer for some people who have lost their jobs in the state-owned industrial enterprises (Nikoloski 2009). However, the recent changes show that service sector gradually becomes to play increasingly important role by absorbing more than half of the employed workforce, whereas the agricultural sector starts to shrink. Given the rigidities in the standard adjustment through employment and wages, less traditional labour market adjustment mechanisms may play a more significant role. Among the alternative labour market adjustment mechanisms we particularly distinguish the non-participation, emigration and employment in the informal sector.

The Macedonian labour market is affected by strong segmentation, meaning that certain social groups such as youths, less skilled workers, and women, face a higher risk of unemployment and inactivity than the rest of the labour force. As a consequence, the high Macedonian unemployment rate has enormous social implications such as rising poverty, income inequality and social exclusion of deprived social segments (Nikoloski 2012). When considering the marginalised categories, we assume that the same labour market segments are the most inclined toward informal employment arrangements or temporary emigration where jobs are characterised with low security and lower wages compared to jobs in the formal sector. Furthermore, the marginalised segments are affected by the fluctuations in the business cycles more than the rest of the labour force which is evident from the last economic downturn.

In addition, the Macedonian labour market is characterised by a relatively stagnant unemployment pool that has been translated into increasing long-term unemployment ${ }^{1}$. For instance, long-term unemployment accounts for more than 80 percent of total unemployment which represents high relative share compared

1 As long-term unemployed are consider those who look for job more than one year; 
to international standards. Long-term unemployment has significantly contributed to an erosion of skills and motivation of unemployed workers, making them less employable over time. The deterioration of skills further reduces the attractiveness of the labour force and contributes to a blurring of the difference between the states of unemployment and non-participation. The long-term unemployed are not viewed by employers as attractive fillers of vacancies, meaning that their employability is relatively weak.

After remaining unemployed for a long period of time, a considerable part of unemployed workers stops looking for jobs and quits the labour force. This is known as the phenomenon of 'discouraged workers', a characteristic for depressed labour markets where labour demand is insufficient and unemployed workers face poor employment prospects. Discouraged workers do not fulfil the requirements of job search as a precondition to be counted as unemployed which means that they are de facto non-participants. On the other hand, they can easily re-enter the labour force if, conditions on the demand side of the labour market improve (Kingdon and Knight 2006). For example, the estimated number of discouraged workers according to the LFS in 2012 was 30322 which represent more that 10 percent of the total number of unemployed.

The size of the employment in the informal sector ${ }^{2}$ in Macedonia is relatively large compared with the more advanced transition countries. For instance, according to the LFS data in 2012 the share of employed in the informal sector was estimated about 22.5 percents. However, having in mind the nature of the informal sector, any assessment based on self-reporting as in the case of LFS, will potentially underestimate its true size. The Macedonian informal sector predominantly consists of small-scale agricultural production carried out by workers with low levels of education who are either employees without stable contracts or unpaid contributing family workers. Thus, workers in the informal sector are usually low skilled or unskilled and they are less competitive in the labour market (Nikoloski et al. 2012). In addition, a majority of these workers experience the so-called informal employment trap' i.e. they face a low probability of exiting the informal employment (Bernabe 2002). At the micro level, there is increased human capital erosion experienced by workers who work in the informal sector due to the labour-intensive characteristics of the informal employment and absence of vocational training.

2 Although there are various terms used to denote the informal sector, we assume that it covers all unrecorded economic activities that are legal by the nature of produced goods and services, but are undertaken in order to meet the basic needs (also known as 'coping strategies').

\section{LITERATURE REVIEW}

The implications of unemployment are various and research has clearly demonstrated that it causes psychological distress. The employment status is widely acknowledged to have a large influence on individual perceptions, with unemployment in particular associated with a strong negative impact on measures of life satisfaction (Winkelmann and Winkelmann 1998; Waters 2000). For instance, the empirical findings show that unemployed have higher levels of perceived stress compared to employed and among the lowest level of psychological wellbeing of all people (Meer 2014). The assumption that unemployment is associated with lower level of wellbeing stems from the fact that unemployed have lower incomes, decreased human and social capital which consequently implies diminished live satisfaction and happiness.

Although unemployment is generally considered as an economic problem, the psychological consequences of the unemployment go beyond the pure economic considerations (Winefield 2002). Namely, unemployment status imposes to individuals and their families additional burden as non-pecuniary costs since employment is not only a source of income, but also provides social relationships, identity in the society and individual self-esteem (Winkelmann and Winkelmann 1998; Tøge 2016). The empirical literature shows that unemployed persons manifest significant symptoms of deteriorated health conditions such as higher incidence of stress, anxiety and depression (Bordea and Pellegrini 2014). Furthermore, higher social capital and communication skills do not appear as significant factors in reducing the harmful effect of unemployment (Winkelmann 2009; Pelzer et al. 2014).

Since unemployment is a stressful experience, coping with unemployment is emotionally demanding situation which varies from person to person. According to Lazarus and Folkman (1984), coping is the "process of attempting to manage the demands created by stressful events that are appraised as taxing or exceeding a person's resources". Coping is typically classified in two categories: efforts to deal with the problem or efforts to deal with the emotions. Hence, coping strategies mediate the potentially negative effects of stressors and thus influence mental health. The development of successful coping behaviours is likely to reduce stress and help a person to solve personal problems and maintain their psychological wellbeing (De Fazio et al. 2016).

The duration of unemployed also affects the perceived stress and optimism about finding a new job. According to the adaptation hypothesis, by the course of time individuals can adapt to unemployment which implied that longer-duration unemployment has 
a smaller effect on self perceived health than does shorter-duration unemployment. Alternative theoretical view is that unemployed do not adapt to unemployment status. In this case, it is assumed that long-term unemployed are more likely to experience the phenomenon of 'discouraged worker' which would subsequently lead to bad self-perceived health (European Commission 2016). This category of workers is considered as marginally attached and is viewed as distinct labour market state lying between the non-attached and the unemployed (Jones and Riddell 1998).

Besides considering unemployment at the individual level, the total unemployment as a macroeconomic phenomenon might affect the individual perceptions and is strongly related to increased reports of bad self-perceived health (Tay and Kuykendall 2014; European Commission 2016). In this context, two competing theories are used to explain the effect of the overall unemployment on the individual perceptions of unemployed people. First, having more unemployed individuals will result in lower psychological wellbeing at aggregate level which, in turn, may exert negative spill-over effects on other members in the society. On the other hand, the prevailing high unemployment rate may become norm for more individuals to be unemployed which subsequently attenuates detrimental effects of personal unemployment (Clark 2003; Oesch and Lipps 2013).

The experience in transition countries shows that socio-political changes had a strong negative impact on individual perceptions of unemployed. Some studies show that even after 20 years of transition, most transition countries have not regained the level of wellbeing they enjoyed at the outset of transition (Gruen and Klasen 2012). According to the empirical evidence, it seems that vulnerable individuals such as adults affected by labour market reform may represent specific affected group (Orosa 2013). For instance, Blanchflower (2001) finds out that most of unemployed in transition countries are unhappy and are dissatisfied with the direction of reform, presumably because it has excluded them. However, the impact of the alternative labour market adjustment mechanisms on the individual perceptions of unemployed workers in transition countries has so far received little attention.

\section{EMPIRICAL ANALYSIS}

As stated above, the Macedonian labour market is characterised with persistent unemployment which can be inter alia attributed to factors that we denote as alternative labour market adjustment mechanisms. While the conventional forms of labour market adjustment through wages and/or working hours are mostly characteristic for the employed workers, the non-standard forms are mainly alternatives for the unemployed. According to our hypothesis, the alternative labour market adjustment mechanisms such as employment in the informal sector, emigration and inactivity may play significant role in shaping the unemployed workers' perceptions of stress and future labour market prospect. This is reasonable since, these forms of adjustment as alternatives in dealing with unemployment provide means of subsistence particularly for disadvantaged labour market segments.

\subsection{Data and sample}

To our knowledge, there is a lack of consistent crosssection data about the unemployed workers' perceptions in Macedonia. In order to estimate to what extent the unemployed are prone toward the nonstandard forms of adjustment we have designed and carried out a survey based on a sample of registered unemployed workers. Although different from the LFS criterion, the advantage of applying the registration criterion for selection can be viewed in the possibility to unambiguously identify eligible respondents in the sample. Due to the lack of exhaustive list of registered unemployed which is considered as confidential, the interviewers had freedom to choose eligible respondents randomly.

The survey was conducted during a reference period from mid October to mid November, 2011. The sample consisted of 2300 unemployed workers which represented about 1 percent of the total number of registered unemployed workers. By taking into account the missing values, the final sample size used for estimation was 2091 unemployed workers. In order to provide representativeness of the sample, the geographical distribution was maintained by selecting a proportional number of respondents with respect to the total number of registered unemployed workers in each branch office. Having in mind the cross-section character of the survey, its weakness is viewed in the fact that it cannot be used to assess changes of unemployed workers' perceptions over time. The structure of the sample according to the main sociodemographic characteristics is given in Table 1.

The survey was traditionally conducted in a pen and paper format by using self-administered questionnaires ${ }^{3}$. The questionnaire consists of 53 questions

3 The questionnaire is available at request which should be sent to the corresponding author. 
Table 1: The sample structure according to various socio-demographic characteristics

\begin{tabular}{|c|c|c|c|c|c|}
\hline \multicolumn{2}{|l|}{ Gender } & \multicolumn{2}{|c|}{ Place of living } & \multicolumn{2}{|l|}{ Age } \\
\hline Male & $50.30 \%$ & Urban & $77.89 \%$ & $15-20$ & $4.09 \%$ \\
\hline Female & $49.70 \%$ & Rural & $22.11 \%$ & $21-25$ & $23.27 \%$ \\
\hline \multicolumn{2}{|l|}{ Education } & \multicolumn{2}{|c|}{ Ethnicity } & $\begin{array}{l}20-50 \\
31-35\end{array}$ & $11.70 \%$ \\
\hline Primary or less & $15.11 \%$ & Macedonian & $81.80 \%$ & $36-40$ & $10.61 \%$ \\
\hline Secondary & $50.35 \%$ & Albanian & $10.21 \%$ & $41-45$ & $10.61 \%$ \\
\hline \multirow[t]{2}{*}{ Higher } & $34.54 \%$ & Turk & $2.26 \%$ & $46-50$ & $8.96 \%$ \\
\hline & & Roma & $2.26 \%$ & $51-55$ & $6.92 \%$ \\
\hline \multicolumn{2}{|l|}{ Marital status } & Serbian & $1.95 \%$ & $56-60$ & $3.61 \%$ \\
\hline Single & $40.43 \%$ & Vlahos & $1.00 \%$ & $61-65$ & $0.87 \%$ \\
\hline Married & $53.66 \%$ & Bosnian & $0.35 \%$ & 65 and more & $0.13 \%$ \\
\hline Divorced & $3.74 \%$ & Other & $0.17 \%$ & & \\
\hline Widowed & $2.18 \%$ & & & & \\
\hline
\end{tabular}

Source: Authors' calculations

that had been previously tested with a pilot survey. Most of the questions are close-ended with multiple choices, i.e. they are accompanied by a range of answers from which the respondent is asked to indicate the most applicable one. Only two questions are open ended, designed in order to get personal opinion from the respondent about the psychological perceptions of being unemployed. Besides the questions about the various economic activities or sources of income we attempted to assess the adjustment mechanisms indirectly by using the time allocation to various activities as well as individual values and perceptions.

\subsection{The alternative labour market adjustment mechanisms}

Among the alternative adjustment mechanisms we pay particular attention to the role of employment in the informal sector, emigration and social transfers. As informal economic activities will be considered only those who are legal in nature but not officially registered such as subsistence farming. The emigration as a coping strategy will include temporary work abroad as well as reliance on remittances from the relatives who are permanent emigrants. Finally, the inactivity will mainly encompass reliance on social transfers including both direct and inter household transfers.

In our empirical analysis $38.3 \%$ of the surveyed unemployed workers declared that they earn income from various types of additional activities that are informal by nature, while half of them declared that other household members also perform such types of activities. With respect to this, we argue that in depressed labour markets which lack job creation in the formal sector, informal employment helps people to enter the workforce by offering an alternative to unemployment or inactivity and, prevents a further decline in living standards.

The majority of the unemployed workers who stated that are informally employed are engaged in subsistence activities such as agriculture, farming and seasonal work in the country that together represent about $60 \%$. On the other hand, the entrepreneurial activities such as running own business, artisanship or own production and trade are represented to lesser extent. Therefore, we can conclude that most of the unemployed workers that operate in the informal sector are usually low skilled or unskilled and perform labour-intensive operations. The above argument is in line with the sectoral reallocation in Macedonia during transition, according to which the share of employment in subsistence agriculture demonstrated a significant rise. Nevertheless, this should not be a general conclusion for the productivity in the informal sector, since in this case we do not include the informal activities performed as a second job by those who are otherwise formally employed.

The income gained from informal activities on average is $34.2 \%$ of the total household incomes, which represents significant financial contribution. However, expressed in absolute terms the average monthly income from informal activities is moderate since one third of the respondents declared to earn less than 100 Euros and another third declared an amount between 100 and 200 Euros. As a consequence, we can argue that unemployed workers are primarily involved in informal businesses that usually operate on a smallscale basis either in the form of self-employment or as micro or small enterprises.

Furthermore, in our empirical analysis we found that $27.7 \%$ of the surveyed unemployed workers 
would emigrate permanently if they had the possibility, whereas $33.9 \%$ have intentions to work abroad temporarily. However, about $46 \%$ of those who declared having intentions to emigrate undertake concrete activities to find work abroad, while the remaining $54 \%$ do not undertake such activities. On the other hand, $11.7 \%$ of the respondents stated they have close relatives who are currently emigrated from the country two thirds of who receive financial aid for covering their costs of living. The share of remittances for this category of households in their total income is about $28.2 \%$, which represents a considerable proportion.

We consider the inactivity as mechanism for labour market adjustment since it provides additional income for the households through various types of social transfers. Moreover, we assume that in Macedonian society dominates the traditional system of values that promote egalitarianism, distributional justice and solidarity. In this context, the inter-household transfers might play important role in maintaining the wellbeing of the households. Namely, in deprived households with one or more unemployed members the income from various sources can be distributed to all members of the household in order to satisfy their basic needs. With respect to this, in our empirical analysis we particularly pay attention to the pensions and social assistance.

Regarding the use of pensions, we revealed that $28.5 \%$ of the surveyed unemployed have retired close relatives in their household. Moreover, $79 \%$ of the respondents confirmed that their retired close relatives participate in covering the costs of living in the household. The average amount of pensions in the sample is about 120 Euros which represents $25 \%$ of the total income for this category of households. On the other hand, we found that only $8.65 \%$ of the respondents or another member of their households receive social assistance from the government. The average amount of the social assistance is about 45 Euros, which represents $12.7 \%$ of the total income for this category of households.

\subsection{The unemployed workers' perceptions of stress}

Generally, unemployment is considered as a stressful experience that negatively affects an individual's perception of his/her overall wellbeing. With respect to this, we attempt to assess unemployed workers' perceptions by asking whether the unemployment causes stressing situation or other health problems. Our analysis shows that the unemployment represents an embarrassing situation for the majority of unemployed workers. For instance, $38.2 \%$ of the
Figure 2: Unemployment as a cause for stress and/or other health problems

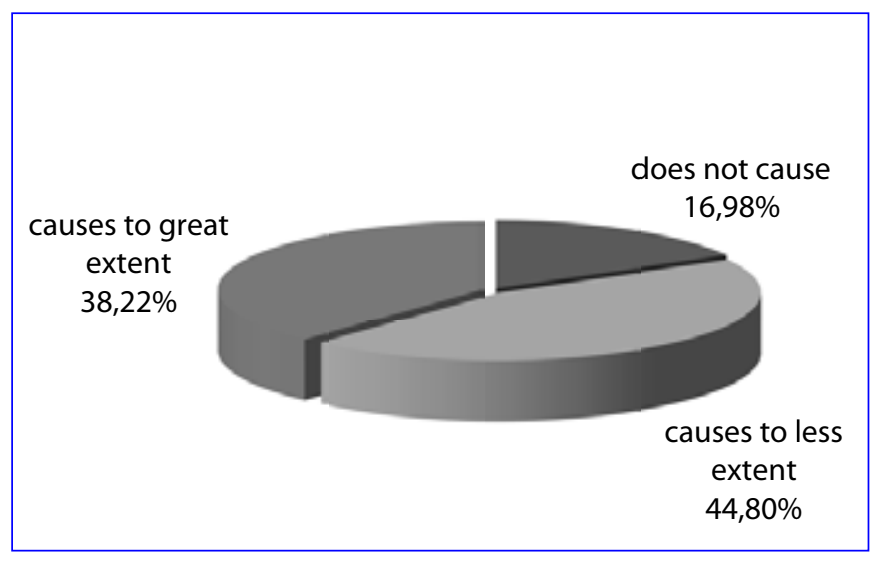

respondents declared that unemployment represents stressing situation and/or causes other health problems to great extent, while these effects prevail to lesser extent among $44.8 \%$ of the interviewed unemployed. The distribution of respondents' opinions with respect to this question is presented in Figure 2.

In order to assess the unemployed workers' perceptions of unemployment as a stressor and/or reason for other health problems, furthermore we estimate a multinomial logistic regression, where as a reference category is considered the choice "does not cause". We divide the possible determinants in four groups: Personal traits, alternative adjustment mechanisms, household characteristics and policy treatment variables. In this context, there might be endogeneity problem suspected since workers to whom unemployment causes more stress are more inclined to emigrate or find informal employment. Hence, we are aware of this common problem in treating the psychological implications of unemployment and we interpret the estimations cautiously. The results from the estimated multinomial logistic regression are presented in Table 2.

From Table 2 we can notice that the relative probability that unemployment causes stress and/or other health problems to less extent rather than it does not cause increases with the age, level of education, duration of unemployment, job searching activity and intention to emigrate. Namely, this probability would increase by $3.3 \%$ for each additional year of age, by $14.2 \%$ for each additional level of education and by $9 \%$ for each additional level of unemployment duration 4 . In addition, the probability that unemployment causes stress to less extent is $17.7 \%$ higher among those respondents who actively search for job and $16.7 \%$ higher among those who have intention to

\footnotetext{
4 The unemployment duration is divided in 10 class intervals with unequal class width.
} 
Table 2: Estimated multinomial logistic regression for perception of stress

\begin{tabular}{|c|c|c|c|c|c|c|}
\hline \multirow[b]{2}{*}{ Variable } & \multicolumn{3}{|c|}{$\begin{array}{l}\text { Unemployment causes stress and/or } \\
\text { other health problems to less extent }\end{array}$} & \multicolumn{3}{|c|}{$\begin{array}{l}\text { Unemployment causes stress and/or } \\
\text { other health problems to great extent }\end{array}$} \\
\hline & Coeff. & $\begin{array}{l}\text { Standard } \\
\text { error }\end{array}$ & $\begin{array}{l}\text { Diff. in odd } \\
\text { ratio }\end{array}$ & Coeff. & $\begin{array}{l}\text { Standard } \\
\text { error }\end{array}$ & $\begin{array}{l}\text { Diff. in odd } \\
\text { ratio }\end{array}$ \\
\hline $\begin{array}{l}\text { Constant } \\
\text { Personal traits }\end{array}$ & -1.5816 & 1.1708 & & $-3.9452^{* * *}$ & 1.2287 & \\
\hline Gender & 0.0469 & 0.1312 & & 0.0875 & 0.1419 & \\
\hline Age & $0.0320^{* * *}$ & 0.0089 & $3.3 \%$ & $0.0680^{* * *}$ & 0.0091 & $7.0 \%$ \\
\hline Marital status & -0.1126 & 0.1350 & & 0.0737 & 0.1394 & \\
\hline Place of living & -0.0182 & 0.1575 & & -0.1079 & 0.1707 & \\
\hline Level of education & $0.1332^{* * *}$ & 0.0476 & $14.2 \%$ & $0.1712^{* * *}$ & 0.0511 & $18.7 \%$ \\
\hline Duration of unemployment & $0.0864^{* * *}$ & 0.0263 & $9.0 \%$ & $0.1884^{* * *}$ & 0.0283 & $20.7 \%$ \\
\hline Actively search for job & $0.1632^{* * *}$ & 0.0627 & $17.7 \%$ & $0.3742^{* * *}$ & 0.0691 & $45.4 \%$ \\
\hline Alternative adjustment mechanisms & & & & & & \\
\hline Has intention to emigrate & $0.1544^{* *}$ & 0.0828 & $16.7 \%$ & $0.3680^{* * *}$ & 0.0894 & $44.5 \%$ \\
\hline $\begin{array}{l}\text { Engaged in informal employment } \\
\text { Household characteristics }\end{array}$ & -0.0738 & 0.1378 & & -0.0943 & 0.1471 & \\
\hline Household size & 0.0040 & 0.0624 & & -0.0047 & 0.0661 & \\
\hline Number of employed members & -0.0447 & 0.0859 & & -0.0899 & 0.0930 & \\
\hline Has another unemployed member(s) & -0.1719 & 0.1398 & & $-0.5078^{* * *}$ & 0.1490 & $-39.8 \%$ \\
\hline Has retired member(s) & -0.1664 & 0.1523 & & $-0.2825^{*}$ & 0.1627 & $-24.6 \%$ \\
\hline Has emigrated member(s) & 0.3012 & 0.1916 & & $0.4514^{* *}$ & 0.2080 & $57.1 \%$ \\
\hline Policy treatment & & & & & & \\
\hline Social assistance beneficiary & 0.1738 & 0.2988 & & -0.2854 & 0.2954 & \\
\hline Health insurance beneficiary & -0.1642 & 0.1304 & & -0.0979 & 0.1418 & \\
\hline Unemployment benefit recipient & -0.3670 & 0.2888 & & -0.4657 & 0.2971 & \\
\hline Participation in active programmes & 0.2163 & 0.2069 & & 0.3511 & 0.2261 & \\
\hline
\end{tabular}

Note: ${ }^{*},{ }^{* *}$ and ${ }^{* * *}$ represent statistical significance at the $10 \%, 5 \%$ and $1 \%$ levels respectively.

emigrate. Thus, being proactive unemployed worker in the Macedonian labour market is associated with higher probability of experiencing stress from unemployment.

The similar and even more pronounced pattern can be observed for the relative probability that unemployment causes stress and/or other health problems to great extent rather than it does not cause. Namely, this probability would increase by $7 \%$ for each additional year of age, by $18.7 \%$ for each additional level of education and by $20.7 \%$ for each additional level of unemployment duration. Furthermore, the probability that unemployment causes stress to great extent is $45.4 \%$ higher among those respondents who actively search for job and $44.5 \%$ higher among those who have intention to emigrate. In addition, this relative probability is $57.1 \%$ greater if the respondent's household has emigrated member(s), whilst it is lower by $39.8 \%$ and $24.6 \%$ in cases the respondent's household has another unemployed member or retired member(s) respectively. The pseudo $\mathrm{R}^{2}$ of this model is 0.083 , while the $p$-value of the calculated $x^{2}$ which is 0.000 leads us to conclude that at least one of the regression coefficients in the model is not equal to zero.

\subsection{The unemployed workers' perceptions of employment prospects}

Besides being a stressful situation, the optimism about finding job in the near future is considered as another psychological aspect of unemployment. With respect to this we asked respondents how they see themselves within a time horizon of five years. The results show that about $15.1 \%$ think they will remain unemployed, whereas $22.7 \%$ do not have opinion. In contrast, about $39.7 \%$ of the respondents hope they will find formal job, while the remaining $22.5 \%$ would search for alternative opportunities such as employment in the informal sector (5.3\%), emigration (13.1\%) or retirement $(4 \%)$. This finding reflects relatively mixed perceptions among unemployed workers regarding their future prospects on the labour market. The distribution of respondents' opinions with respect to the future labour market prospects is presented in Figure 3.

In order to assess the factors that influence the unemployed workers' perceptions of future employment prospects we further estimate a multinomial logistic regression, where as a reference category is 
Figure 3: Perception of the labour market status after 5 years

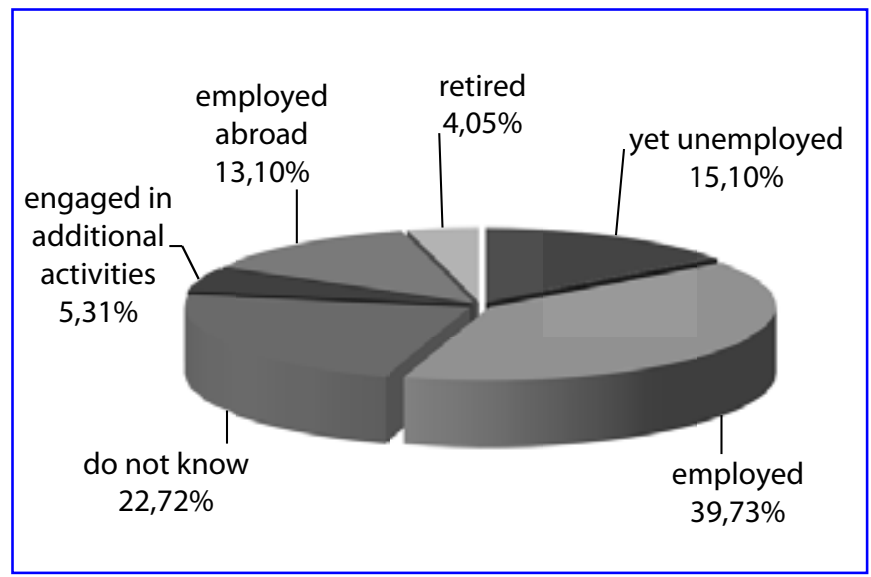

considered "perceives himself after 5 years as yet unemployed". Similarly, as in the case of estimating the impact of unemployment as a stressor, we divide the possible determinants in four groups: Personal traits, alternative adjustment mechanisms, household characteristics and policy treatment. Again, we are aware about the possible endogeneity problem and we interpret the estimates with caution. The results from the estimated multinomial logistic regression are presented in Table 3.

From Table 3 we can notice that female respondents have on average $34.4 \%$ lower probability to perceive as employed after 5 years relative to unemployed as reference category, while this probability decreases by $7.9 \%$ and $25.2 \%$ for each additional year of age and additional level of unemployment duration respectively. In contrast, the relative probability of perceiving as employed after 5 years rather than unemployed increases by $33 \%$ for each additional level of education. In addition, this probability is about $76 \%$ and $84.4 \%$ higher for those respondents who reported that actively search for job and have another unemployed member in the household respectively.

Furthermore, we observe that the relative probability of being uncertain about the labour market status after 5 years is $33.8 \%$ and $28.4 \%$ lower for female unemployed and those living in rural areas respectively. In addition, the uncertainty decreases by $4.2 \%$ and $14.1 \%$ for each additional year of age and

Table 3. Estimated multinomial logistic regression for perception of employment prospects

\begin{tabular}{|c|c|c|c|c|c|c|c|c|c|}
\hline \multirow[b]{2}{*}{ Variable } & \multicolumn{3}{|c|}{$\begin{array}{c}\text { Perceives himself after } 5 \text { years as } \\
\text { employed }\end{array}$} & \multicolumn{3}{|c|}{$\begin{array}{c}\text { Perceives himself after } 5 \text { years as } \\
\text { uncertain }\end{array}$} & \multicolumn{3}{|c|}{$\begin{array}{l}\text { Perceives himself after } 5 \text { years as } \\
\text { engaged in the informal sector }\end{array}$} \\
\hline & Coeff. & $\begin{array}{c}\text { Standard } \\
\text { error }\end{array}$ & $\begin{array}{l}\text { Diff. in odd } \\
\text { ratio }\end{array}$ & Coeff. & $\begin{array}{l}\text { Standard } \\
\text { error }\end{array}$ & $\begin{array}{l}\text { Diff. in odd } \\
\text { ratio }\end{array}$ & Coeff. & $\begin{array}{l}\text { Standard } \\
\text { error }\end{array}$ & $\begin{array}{l}\text { Diff. in odd } \\
\text { ratio }\end{array}$ \\
\hline Constant & 2.0073 & 1.3450 & & 1.7262 & 1.2824 & & 3.9160 & 1.856 & \\
\hline \multicolumn{10}{|l|}{ Personal traits } \\
\hline Gender & $-0.4223^{* * *}$ & 0.1657 & $-34.4 \%$ & $-0.4129^{* *}$ & 0.1637 & $-33.8 \%$ & $-0.5141^{* *}$ & 0.2417 & $-40.2 \%$ \\
\hline Age & $-0.0818^{* * *}$ & 0.0096 & $-7.9 \%$ & $-0.0434^{* * *}$ & 0.0090 & $-4.2 \%$ & $-0.0530^{* * *}$ & 0.0138 & $-5.2 \%$ \\
\hline Marital status & 0.0383 & 0.1622 & & 0.2296 & 0.1564 & & 0.1656 & 0.2307 & \\
\hline Place of living & -0.3045 & 0.1876 & & $-0.3346^{*}$ & 0.1836 & $-28.4 \%$ & -0.0955 & 0.2691 & \\
\hline Level of education & $0.2855^{* * *}$ & 0.0583 & $33 \%$ & 0.0648 & 0.0546 & & $0.2818^{* * *}$ & 0.0872 & $32.6 \%$ \\
\hline Duration of unemployment & $-0.2910^{* * *}$ & 0.0345 & $-25.2 \%$ & $-0.1524^{* * *}$ & 0.0349 & $-14.1 \%$ & $-0.1846^{* * *}$ & 0.0487 & $-16.9 \%$ \\
\hline Actively search for job & $0.5652^{* * *}$ & 0.0768 & $76 \%$ & $0.2215^{* * *}$ & 0.0697 & $24.8 \%$ & 0.1053 & 0.1051 & \\
\hline \multicolumn{10}{|l|}{ Alternative adjustment mechanisms } \\
\hline Has intention to emigrate & -0.1428 & 0.1038 & & 0.0214 & 0.1011 & & $-0.3417^{* *}$ & 0.1584 & $-28.9 \%$ \\
\hline Engaged in informal employment & 0.0705 & 0.1652 & & 0.0589 & 0.1624 & & $-0.5343^{* *}$ & 0.2392 & $-41.4 \%$ \\
\hline \multicolumn{10}{|l|}{ Household characteristics } \\
\hline Household size & -0.0020 & 0.0741 & & -0.0055 & 0.0717 & & -0.0475 & 0.1090 & \\
\hline Number of employed members & 0.1504 & 0.1108 & & $0.1836^{*}$ & 0.1096 & $20.2 \%$ & 0.0862 & 0.1611 & \\
\hline Has another unemployed member(s) & $0.6122^{* * *}$ & 0.1694 & $84.4 \%$ & $0.5389^{* * *}$ & 0.1683 & $71.4 \%$ & -0.0971 & 0.2441 & \\
\hline Has retired member(s) & 0.1429 & 0.1834 & & -0.0042 & 0.1797 & & $-0.4960^{* *}$ & 0.2543 & $-39.1 \%$ \\
\hline Has emigrated member(s) & -0.0321 & 0.2506 & & -0.0681 & 0.2416 & & 0.0753 & 0.3717 & \\
\hline \multicolumn{10}{|l|}{ Policy treatment } \\
\hline Social assistance beneficiary & 0.3640 & 0.2958 & & 0.0287 & 0.2557 & & 0.2059 & 0.4123 & \\
\hline Health insurance beneficiary & -0.2409 & 0.1669 & & -0.2321 & 0.1661 & & 0.2282 & 0.2419 & \\
\hline Unemployment benefit recipient & 0.4211 & 0.3000 & & 0.3546 & 0.2814 & & -0.2253 & 0.3975 & \\
\hline Participation in active programmes & -0.3940 & 0.2761 & & -0.1204 & 0.2816 & & -0.3066 & 0.3728 & \\
\hline
\end{tabular}

Note: ${ }^{*},{ }^{* *}$ and ${ }^{* * *}$ represent statistical significance at the $10 \%, 5 \%$ and $1 \%$ levels respectively. 
Table 3: (continues) Estimated multinomial logistic regression for perception of employment prospects

\begin{tabular}{|c|c|c|c|c|c|c|}
\hline \multirow[b]{2}{*}{ Variable } & \multicolumn{3}{|c|}{$\begin{array}{l}\text { Perceives himself after } 5 \text { years as } \\
\text { employed abroad }\end{array}$} & \multicolumn{3}{|c|}{$\begin{array}{c}\text { Perceives himself after } 5 \text { years as } \\
\text { retired }\end{array}$} \\
\hline & Coeff. & $\begin{array}{l}\text { Standard } \\
\text { error }\end{array}$ & $\begin{array}{l}\text { Diff. in } \\
\text { odd ratio }\end{array}$ & Coeff. & $\begin{array}{l}\text { Standard } \\
\text { error }\end{array}$ & $\begin{array}{l}\text { Diff. in } \\
\text { odd ratio }\end{array}$ \\
\hline Constant & 0.7840 & 1.6911 & & -12.5644 & 3.0936 & \\
\hline \multicolumn{7}{|l|}{ Personal traits } \\
\hline Gender & $-0.6488^{* * *}$ & 0.2012 & $-47.7 \%$ & -0.0691 & 0.3212 & \\
\hline Age & $-0.0946^{* * *}$ & 0.0129 & $-9 \%$ & $0.2338^{* * *}$ & 0.0308 & $26.3 \%$ \\
\hline Marital status & 0.2005 & 0.1975 & & 0.2959 & 0.2741 & \\
\hline Place of living & $-0.8299^{* * *}$ & 0.2436 & $-56.4 \%$ & 0.0481 & 0.3884 & \\
\hline Level of education & 0.0897 & 0.0711 & & $0.1727^{*}$ & 0.1028 & $18.9 \%$ \\
\hline Duration of unemployment & $-0.2439^{* * *}$ & 0.0415 & $-21.6 \%$ & $-0.1859^{* * *}$ & 0.0619 & $-17 \%$ \\
\hline Actively search for job & $0.2691^{* * *}$ & 0.0929 & 30.9 & -0.0608 & 0.1308 & \\
\hline \multicolumn{7}{|l|}{ Alternative adjustment mechanisms } \\
\hline Has intention to emigrate & $1.5175^{* * *}$ & 0.1438 & $356.1 \%$ & -0.1867 & 0.2290 & \\
\hline Engaged in informal employment & $-0.3356^{*}$ & 0.2001 & $-28.5 \%$ & -0.2983 & 0.3248 & \\
\hline \multicolumn{7}{|l|}{ Household characteristics } \\
\hline Household size & 0.0510 & 0.0922 & & 0.1664 & 0.1423 & \\
\hline Number of employed members & 0.0144 & 0.1337 & & 0.2953 & 0.2069 & \\
\hline Has another unemployed member(s) & $0.5356^{* * *}$ & 0.2044 & $70.8 \%$ & 0.0759 & 0.3270 & \\
\hline Has retired member(s) & -0.0004 & 0.2228 & & -0.3075 & 0.3332 & \\
\hline Has emigrated member(s) & -0.4461 & 0.2890 & & 0.1491 & 0.4446 & \\
\hline \multicolumn{7}{|l|}{ Policy treatment } \\
\hline Social assistance beneficiary & $0.8469^{* *}$ & 0.4074 & $133.2 \%$ & 0.5763 & 0.4758 & \\
\hline Health insurance beneficiary & -0.1357 & 0.2031 & & 0.5070 & 0.3458 & \\
\hline Unemployment benefit recipient & -0.0226 & 0.3907 & & $-1.3583^{* * *}$ & 0.3955 & $-74.3 \%$ \\
\hline Participation in active programmes & 0.0249 & 0.3393 & & 0.1447 & 0.5516 & \\
\hline
\end{tabular}

Note: ${ }^{*},{ }^{* *}$ and ${ }^{* * *}$ represent statistical significance at the $10 \%, 5 \%$ and $1 \%$ levels respectively.

additional level of unemployment duration respectively. In contrast, the uncertainty about the future labour market prospects is $24.8 \%$ higher for those who actively search for job, $20.2 \%$ higher for an additional employed member in the household and $71.4 \%$ higher if the respondent's household has another unemployed member.

We further notice that relative probability of perceiving as engaged in the informal sector after 5 years is $40.2 \%$ lower for female, while it decreases by $5.2 \%$ and $16.9 \%$ for each additional year of age and unemployment duration level respectively. In contrast, this probability increases by $32.6 \%$ for each additional level of education. Additionally, the relative probability of perceiving as informally employed after 5 years is $28.9 \%$ lower if the respondent manifests intention to emigrate, $41.4 \%$ lower if the respondent is currently informally employed and $39.1 \%$ lower if the respondent's household has retired member.

Moreover, it is noticeable that relative probability of perceiving as employed abroad after 5 years is $47.7 \%$ lower for female unemployed, while it is $56.4 \%$ lower for respondents living in rural areas. In addition, this probability is $9 \%$ and $21.9 \%$ lower for each additional year of age and additional unemployment duration respectively. In contrast, perceiving as employed abroad is $30.9 \%$ more probable for those who actively search for job and about 3.5 times more probable for those who have intention to emigrate. Finally, the relative probability of perceiving as employed abroad is $28.5 \%$ lower for those who are engaged in informal employment, but $70.8 \%$ and $133.2 \%$ higher if the respondent's household has another unemployed member and the respondent is social assistant beneficiary respectively.

Finally, we can notice that relative probability of perceiving as retired after 5 years increases by $26.3 \%$ for each additional year of age and increases by $18.9 \%$ for each additional level of education. In contrast, this probability is $17 \%$ lower for each additional unemployment duration level and is $74.3 \%$ lower if the respondent is unemployment benefit recipient. The pseudo $R^{2}$ of this model is 0.218 , while the $p$-value of the calculated $\chi^{2}$ which is 0.000 leads us to conclude that at least one of the regression coefficients in the model is not equal to zero. 


\section{DISCUSSION AND POLICY IMPLICATIONS}

In this paper we have analysed the psychological implications of high and persistent unemployment in Macedonia with particular accent on unemployed workers' perceptions of stress and future employment prospects. With this regard, we have been particularly interested to assess the role of the alternative mechanisms such as employment in the informal sector, emigration and non-participation in shaping the unemployed workers' perceptions by cushioning the social and economic consequences of the high and persistent unemployment. For this purpose, we have carried out a survey in order to empirically assess the extent to which these adjustment mechanisms absorb a part of the unemployed workforce and/or contribute to their household income, which indirectly affects their individual perceptions of unemployment.

Considering the employment in the informal sector we found that considerable number of unemployed workers is engaged in various forms of informal employment. Furthermore, we revealed that income earned from additional informal activities represents more than one third of the total household income. Hence, employment in the informal sector alongside other forms of labour market adjustment significantly contributes to the well-being of the unemployed workers. However, most of the informal arrangements of the unemployed workers are low-productivity and small-scale predominantly in the agricultural and farming sector.

With respect to emigration we found that more than half of unemployed workers if they have the possibility will emigrate either permanently or temporarily. This intention is particularly emphasised among those who perceive unemployment as stressing situation and those whose living standard was the mostly affected by the recent economic crisis. Moreover, we revealed that only small proportion of unemployed have emigrated close relatives, but they heavily rely on the remittances that receive from them. Therefore, remittances alongside other forms of labour market adjustment significantly contribute to the well-being of the unemployed workers.

Regarding the unemployed workers' perceptions of stress, we found that the level of stress increases with the age, level of education and unemployment duration. From the point of view of human capital theory, these results are somewhat expected since the opportunity cost of unemployment increases with the level of education, while longer duration of unemployment has detrimental effects on the accumulated human capital. In addition, the unemployment is more stressful experience for those who actively search for job and those who manifest intention to emigrate and/or have emigrated household members. Hence, by considering the emigration as an alternative coping strategy, the unemployed workers experience more stress which most probably is due to the related higher uncertainty. In contrast, having another unemployed or retired member(s) in the household would reduce the perceived level of stress that might be attributed to the easier adaptation to unemployment or support from inter-household transfers.

Furthermore, we revealed that the perception of future employment prospects by the unemployed workers is a complex phenomenon. In this context, the optimism to perceive as employed is particularly pronounced among those who actively search for job and have other unemployed household members. A similar pattern can be observed among those who are uncertain about their future labour market status which points out to an added worker effect as a response to a loss of real income due to unemployment. The perception of employment in the informal sector and emigration as alternatives to unemployment is more pronounced among younger, male and shortterm unemployed. Generally, the unemployed workers consider the engagement in the informal sector as temporary solution to unemployment since being actually employed in the informal sector reduces the probability of perceiving as informally employed in the future. In contrast, the emigration has been considered as more prospective coping strategy which is consistent with the actual workers' intentions to emigrate and job searching behaviour.

From this analysis of unemployed workers' perceptions of stress and future employment prospects we have learned useful lessons that can guide decision makers in designing and applying appropriate policy measures in order to increase the employability and improve the psychological wellbeing of unemployed workers. First, the labour market issues should be tackled on both demand and supply side which means that increased number of created jobs must be accompanied with wise investments on the side of the quality of the labour force. Second, the possible intervention programmes should be tailored to suit the individual since the experience of unemployment is not the same for every unemployed person. In this context, the labour market segmentation might have serious negative implications on the labour market functioning that have to be set off by using appropriate policy measures. Third, a greater accent should be given to the active labour market policies and their complementarities with passive labour market policies. With respect to this, it is advisable to combine the job searching assistance with psychological assistance for those unemployed who may need it. Fourth, the 
process of formalisation of jobs in the informal part of the economy has to be done prudently with an accent to the sustainability of the formalised jobs. Since, the informal employment has been generally considered as a strategy of last resort, the process of formalisation has to bring to unemployed workers a decent work defined as simultaneous pursuit of several objectives such as: income opportunities, social protection, fundamental rights at work and social dialogue. Fifth, the role of social transfers to non-participants should be reassessed and adequately redesigned in the light of the planned economic development. Hence, the very nature of economic development calls for addressing social protection and employment and income opportunities together, as part of the same policy package.

\section{REFERENCES}

Bernabe, S. 2002. Informal Employment in Countries in Transition: A Conceptual Framework, Centre for Analysis of Social Exclusion, London, Working paper No.56.

Blanchard, O. 1997. The Economics of Post-Communist Transition, Oxford: Clarendon Press.

Blanchflower, D. 2001. Unemployment, well-being, and wage curves in Eastern and Central Europe, Journal of the Japanese and International Economies, 15(4): 364-402.

Bordea, E. And Pellegrini, A. 2014. The Evaluation of the Levels of Stress, Anxiety and Depression for the Unemployed Persons, International Journal of Academic Research, 6(1): 325-332.

Cazes, S. and Nesporova, A. 2003. Labour Markets in Transition, Balancing Flexibility and Security in Central and Eastern Europe, International Labour Office, Geneva.

Clark, A. 2003. Unemployment as a Social Norm: Psychological Evidence from Panel Data, Journal of Labour Economics, 21(2): 323-351.

De Fazio et al. 2016 Unemployment, perceived health status and coping: A study in Southern Italy, Work 53: 219-224.

European Commission 2016. Duration of Unemployment and Self-Perceived Health in Europe.

European Training Foundation 2007. Labour markets in the Western Balkans, Challenges for the future.

Gruen, C. and Klasen, S. 2012. Has transition improved wellbeing?, Economic Systems, 36(1): 11-30.

Jones, S. and Riddell, C. 1998. The Measurement of Unemployment: An Empirical Approach, Econometrica, 67(1): 147-162.

Kingdon, G. and Knight, J. 2006. The Measurement of Unemployment when Unemployment is high, Labour Economics, 13(3): 291-315.
Lazarus, R. And Folkman, S. 1984 Stress, Appraisal and Coping, New York: Springer.

Meer, P. 2014. Gender, Unemployment and Subjective WellBeing: Why Being Unemployed is Worse for Men than for Women, Social Indicators Research, 115: 23-44.

Micevska, M. 2008. The Labour Market in Macedonia: A Labour Demand Analysis, LABOUR, 22(2): 345-368.

Nikoloski, D. 2009. The sustainable rate of unemployment in transition countries - A case study for Macedonia, VDM Verlag.

Nikoloski, D. 2012. The determinants of the labour market segmentation in transition countries with particular reference to Macedonia, Der Donauraum, 52(3-4): 429-444.

Ochsen, C. 2011. Subjective Well-Being and Aggregate Unemployment: Further Evidence, Scottish Journal of Political Economy, 58(5): 634-655.

Oesch, D. and Lipps, O. 2013. Does Unemployment Hurt Less if There is More of it Around? A Panel Analysis of Life Satisfaction in Germany and Switzerland, European Social Review, 29(5): 955-967.

Orosa, F. 2013. Psychosocial wellbeing in the Central and Eastern European transition: An overview and systematic bibliographic review, International Journal of Psychology, 48(4): 481-491.

Pechijareski, L. and Rocheska S. 1998. Transition in Macedonia, between theory and practice, NIP Metafora, Prilep.

Pelzer, B., Schaffrath, S. and Vernaleken, I. 2014. Coping with unemployment: The impact of unemployment on mental health, personality, and social interactions skills, Work, 48: 289-295.

Svejnar, J. 2002. Labour Market Flexibility in Central and East Europe, William Davidson Working Paper, 496.

Tay, L. and Kuykendall, L. 2013. Promoting happiness: The malleability of individual and societal subjective wellbeing, International Journal of Psychology, 48(3): 159-176.

Tøge, A. 2016. Health effects of unemployment in Europe (2008-2011): a longitudinal analysis of income and financial strain as mediating factors, International Journal of Equity and Health, Vol.15, No.75.

Waters, L. 2000. Coping with unemployment: a literature review and presentation of a new model, International Journal of Management Reviews, 2(2): 169-182.

Winefield, A. 2002. Unemployment, Underemployment, Occupational Stress and Psycological Well-Being, Australian Journal of Management, 27 Special issue, pp. 137-148.

Winkelmann, L. and Winkelmann, R. 1998. Why Are the Unemployed So Unhappy? Evidence from Panel Data, Economica, 65: 1-15.

Winkelmann, R. 2009. Unemployment, Social Capital, and Subjective Well-Being, Journal of Happiness Studies, 10: 421-430. 